\title{
A 5 W High Efficiency Class AB Power Amplifier for LTE Base Station Application
}

\author{
A. S. M. Alqadami ${ }^{1}$, S. Madhuwantha ${ }^{2}$, R. Farrell ${ }^{3}$, J. Dooley ${ }^{4}$ \\ 1,2,3,4Electronic Enginnering Department, Maynooth University, \\ Maynooth, Kildare, Ireland \\ 1'Abdulrahman.alqadami.2017@numi.ie
}

\begin{abstract}
$\square \square \square[\square \square-$ This paper presents the design of a Class AB power amplifier operating at a frequency band of $3.4 \mathrm{GHz}-3.7 \mathrm{GHz}$ for LTE base station applications. The proposed design is targeted for a compact, low cost, high efficiency, and good linearity features. It based on GaN HEMT CGH40006P device manufactured by Wolfspeed/Cree. The design procedure and assessment of the presented power amplifier are described in this paper. The proposed input and output matching networks with stepped tapered microstrip transmission line have enhanced the transmission coefficients of the power amplifier, resulting in improvement of overall performance. The drain voltage and current waveforms are demonstrated to ensure the appropriate biasing point of class $A B$. At $1 \mathrm{~dB}$ compression, the simulated results of the proposed class $A B$ power amplifier with one tone input signal delivers power added efficiency of $59 \%$, and $38 \mathrm{dBm}$ output power. With code division multiple access (CDMA) signal, the power amplifier delivers a $51.9 \%$ of PAE, adjacent channel power ratio (ACPR) of below than $-28.5 \mathrm{dBc}$ at $2.25 \mathrm{MHz}$ offsets, and delivers $37 \mathrm{dBm}(\sim 5 \mathrm{~W})$ output power.
\end{abstract}

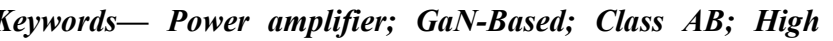

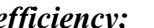

\section{INTRODUCTION}

High efficiency and linearity power amplifiers are extremely desirable by wireless telecommunication equipment manufacturers to meet the requirements of new technology of wireless communication systems. Power amplifiers play a significant role in wireless communication system performance. Its features strongly effect the entire system performance as it serves to enhance the signal to competently cope with varying its characteristics while ensuring efficient transmissions, and cost effectiveness [1]. The linearity of the power amplifier is also very important for transmitting complex modulation schemes that provide high data rates. As the modulated signal often has non-constant envelope modulation with with high Peak to Average Power Ratio (PAPR) such modulation schemes are realized in CDMA and OFDM systems [2-4]. Therefore, power amplifiers must be appropriately designed to ensure efficiency and linearity [5].

Designing a power amplifier involves numerous challenges such as the trade-off between linearity, efficiency, gain, output power, stability, input and output reflections and device selection [6]. Class $\mathrm{AB}$ power amplifiers are compromise between Class-A and Class-B modes in terms of linearity and efficiency [1], [7]. Typically, the device is biased to a quiescent point, which is somewhere in the region between the cut-off point and the Class A bias point. In this case, the device will be conducting current for more than half cycle, and less than a full

This publication has emanated from research conducted with the financial support of Science Foundation Ireland (SFI) and is co-funded under the European Regional Development Fund under Grant Number 13/RC/2077 cycle which results in an efficiency between $50 \%-78 \%$ and better linearity than class B [8].

Transistor selection is an important step in designing power amplifier [5]. There are many device technologies such as laterally diffused metal oxide semiconductor (LDMOS), gallium arsenide (GaAs), and gallium nitride $(\mathrm{GaN})[9,10]$. Each device has its advantages and limitations. In this design, a Gallium Nitride (GaN) High Electron Mobility Transistor (HEMT) is chosen due to its superior performance at microwave frequencies [11]. GaN HEMTs are promising devices, as they ensure large bandwidth, high power density, high breakdown voltage, high gain, and provide high level of robustness, stability thermal conductivity and heat capacity $[12,13]$.

In this paper, a 5 Watt high efficiency class $A B$ power amplifier based on GaN HEMT device is designed using Advanced Design System (ADS2016) software. It operates at 3.4 GHz-3.7 GHz for LTE base station application. Section II discusses the design methodology including biasing networks, input and output matching networks, decoupling, and stability circuit to achieve optimal trade-off between efficiency, linearity and reflection coefficients. In Section III, the power amplifier is characterized, the simulation results include transmission coefficients, small signal gain, PAE, output power, and ACPR with different input signals. This work is concluded in Section IV.

\section{Design Procedure of Class AB Power AmPlifier}

Table I presents the specification of the proposed Class AB power amplifier. A GaN HEMT from CREE, the CGH40006P, is selected. For the board substrate RO4350B, from Rogers Corp., with relative permittivity of $\varepsilon_{\mathrm{r}}=3.8$, dielectric loss tangent of $\tan _{\delta}=0.0031$, and thickness of $0.762 \mathrm{~mm}$ is chosen for the proposed design due to its promising features such as reliability and low dielectric losses.

TABLE I. THE PROPOSED CLASS AB POWER AMPLIFIER SPECIFICATIONS

\begin{tabular}{cc}
\hline \hline Parameters & Specification \\
\hline Operating Frequency & $(3.4-3.7) \mathrm{GHz}$ \\
Bandwidth & $300 \mathrm{MHz}$ \\
Output power & $37 \mathrm{dBm}$ \\
PAE & $>50 \%$ \\
Gain & $>15 \mathrm{~dB}$ \\
Return loss & $<-15 \mathrm{~dB}$
\end{tabular}

To ensure class AB mode operation, a DC simulation for the nonlinear device (CGH40006P) model was performed using ADS 2016 software to obtain the I-V curve and selecting a 
proper Class $\mathrm{AB}$ basing point. Fig. 1 shows the I-V characteristics of the selected device. By observing the device's $\mathrm{I}-\mathrm{V}$ characteristics, the operating point for Class AB mode is chosen at drain current $\mathrm{I}_{\mathrm{DS}}=308 \mathrm{~mA}$, gate voltage $\mathrm{V}_{\mathrm{GS}}=-2.2 \mathrm{~V}$. It is located below the Class $A$, and above the pinch-off point (Class B). The chosen operating point ensures that the device's conduction angle is higher than $180^{\circ}$ and less than $360^{\circ}$ resulting in a compromise between linear and efficient operation.

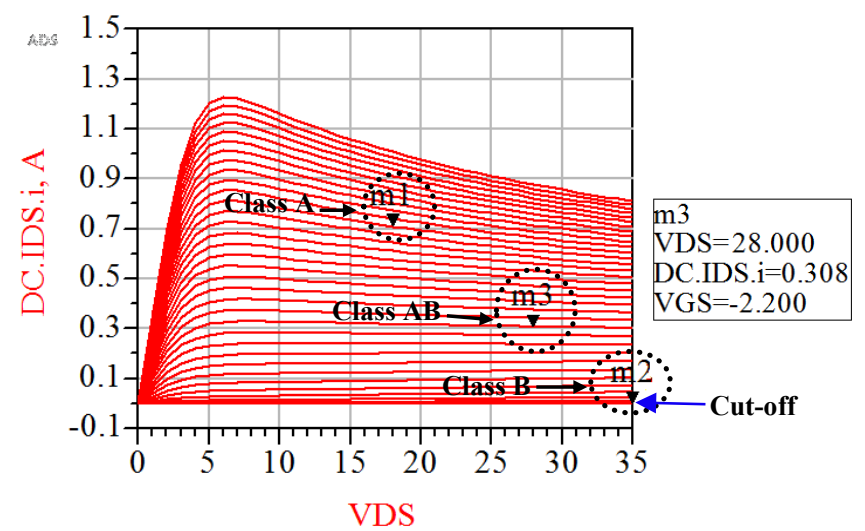

Fig. $1 \mathrm{I}-\mathrm{V}$ curves for CGH40006P device biased at $\mathrm{Vgs}=2 \mathrm{~V}$ to $3 \mathrm{~V}$ to $-3.5 \mathrm{~V}$ and $\mathrm{Vds}=0 \mathrm{~V}$ to $35 \mathrm{~V}$.

The input and output matching networks of the proposed Class $\mathrm{AB}$ power amplifier are designed using stepped impedance and open stubs matching filter to match the typically $50 \Omega$ input and output impedance to the given transistor's source and load impedance for optimal performance. The input matching network is designed to match a $50 \Omega$ to transistor's source impedance $2.57-\mathrm{j} 6.74 \Omega$ within the operating frequency band (3.4 GHz-3.7 GHz), see Fig. 2 (a). A single stub and stepped transmission line is used to filter out all unwanted harmonic components while pass signals within the desired frequency band. To improve the stability of the device, parallel $\mathrm{RC}$ circuit is placed before the gate of the transistor as shown in Fig. 2 (a). Similar to the input matching network, an output matching network is designed with stepped tapered microstrip line and two open stubs to match a $12.5+\mathrm{j} 23.1 \Omega$ output impedance to the customary $50 \Omega$ output impedance as shown in Fig. 2(b). The input and output match response of the proposed design for $3.4 \mathrm{GHz}-3.7 \mathrm{GHz}$ is shown in Fig. 2 (c).

Drain and gate voltages feed the transistor by similar DC biasing networks through high reactance $\mathrm{RF}$ choke $\left(\mathrm{L}_{1}\right.$, and $\left.\mathrm{L}_{2}\right)$, and RF decoupling and voltage stabilizing capacitors $\left(\mathrm{C}_{5}-\mathrm{C}_{11}\right)$ as can be seen in Fig. 3.

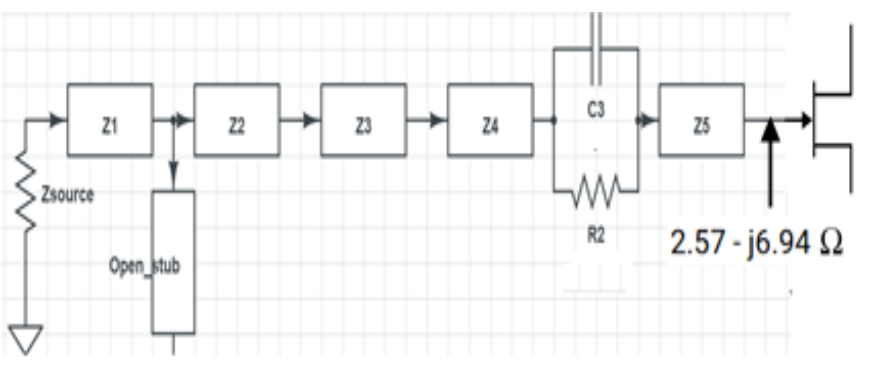

(a)

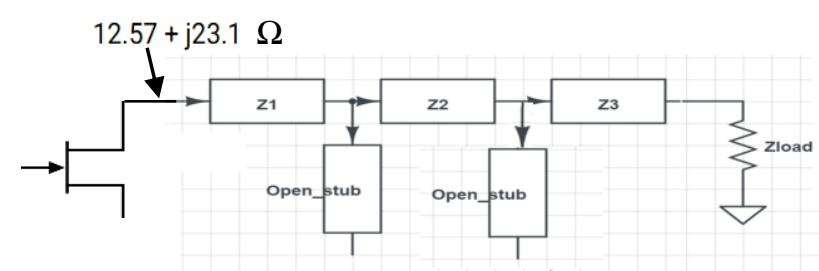

(b)

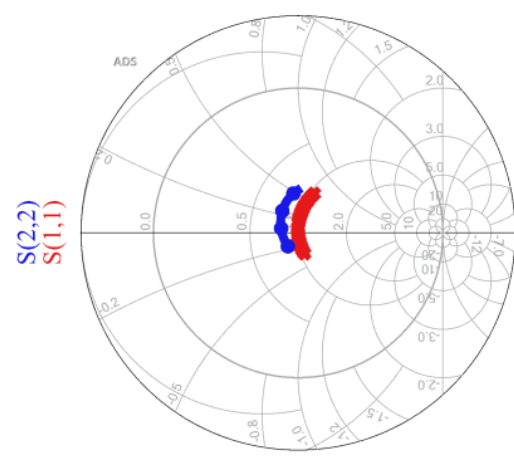

freq $(3.400 \mathrm{GHz}$ to $3.700 \mathrm{GHz})$

(c)

Fig. 2 Input and output matching networks, (a) Input matching network, (b) output matching network, (c) simulated input and output match response seen at the input (S11) and output (S22) of the proposed power amplifier within operation band $(3.4 \mathrm{GHz}-3.7 \mathrm{GHz})$.

Fig. 3 (a), and (b) illustrates the full design schematic and layout of the proposed class $\mathrm{AB}$ power amplifier, respectively. Parameters values are demonstrated in Table II.
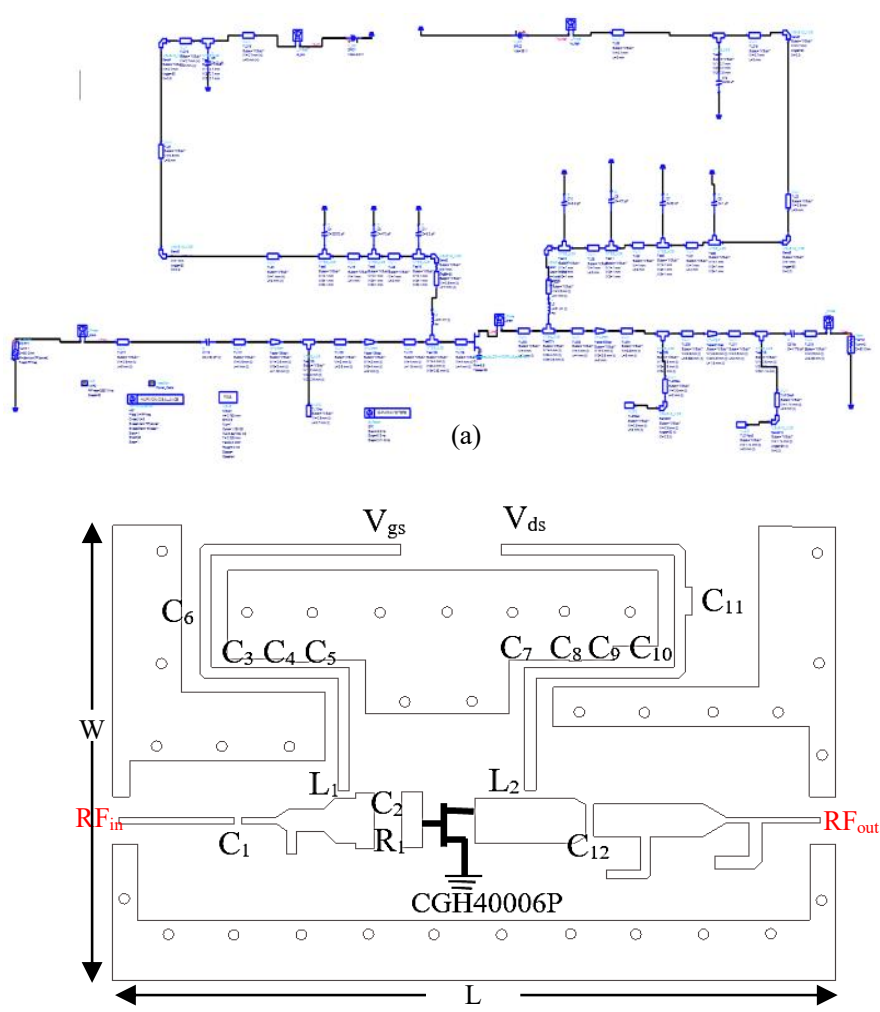

(b)

Fig. 3 Schematic and layout of the proposed design, (a) schematic, (b) layout. 
TABLE II. THE PROPOSED ClASS AB POWER AMPLIFIER PARAMETERS

\begin{tabular}{cccc} 
Parameters & Value & Parameters & Value \\
\hline $\mathrm{C}_{1}, \mathrm{C}_{12}$ & $4.7 \mathrm{pF}$ & $\mathrm{W}$ & $40 \mathrm{~mm}$ \\
$\mathrm{C}_{2}$ & $2 \mathrm{pF}$ & $\mathrm{L}$ & $56 \mathrm{~mm}$ \\
$\mathrm{C}_{3}, \mathrm{C}_{4}$ & $8.2 \mathrm{pF}$ & $\mathrm{V}_{\mathrm{gs}}$ & $-2.2 \mathrm{~V}$ \\
$\mathrm{C}_{4}, \mathrm{C}_{8}$ & $470 \mathrm{pF}$ & $\mathrm{V}_{\mathrm{ds}}$ & $28 \mathrm{~V}$ \\
$\mathrm{C}_{3}, \mathrm{C}_{9}$ & $0.33 \mathrm{uF}$ & $\mathrm{R}_{1}$ & $4.7 \Omega$ \\
$\mathrm{C}_{6}$ & $10 \mathrm{uF}$ & - & - \\
$\mathrm{C}_{11}$ & $33 \mathrm{pF}$ & - & - \\
\hline \hline
\end{tabular}

\section{RESULTS AND DISCUSSION}

Fig. 4 (a) and (b) illustrates the simulated small signal Sparameters of the presented Class $\mathrm{AB}$ power amplifier. It can be observed that the input and output reflections $\left(\mathrm{S}_{11}\right.$ and $\left.\mathrm{S}_{22}\right)$ are lower than $-10 \mathrm{~dB}$ within the operating frequency band results, indicating better load matching and efficient transmitting capability. A small signal gain $\left(\mathrm{S}_{21}\right)$ of $15 \mathrm{~dB}$ is achieved as can be seen in Fig. 4 (b).

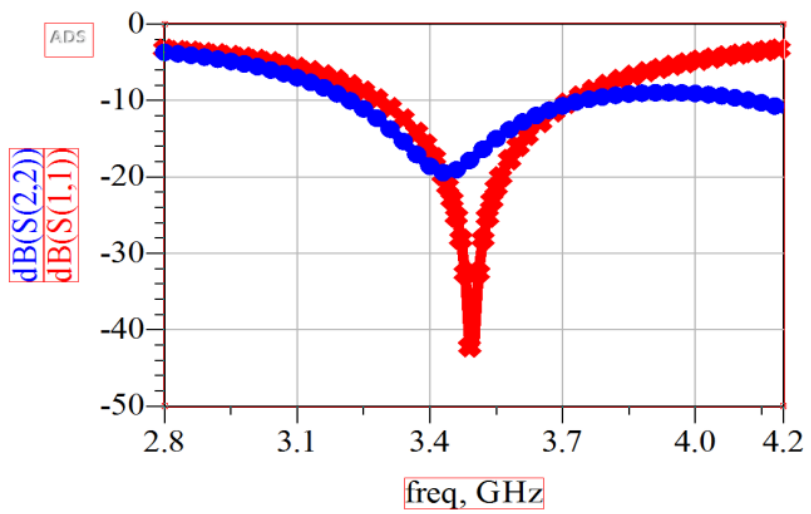

(a)

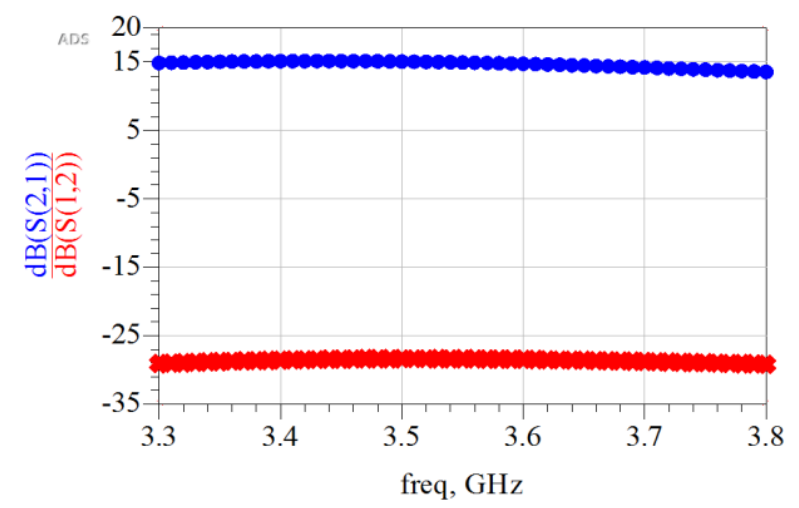

(b)

Fig. 4 Simulated S-parameters of the proposed design, (a) $S_{11}$ and $S_{22}$, (b) $S_{21}$, and $\mathrm{S}_{12}$.

First, performance of the proposed power amplifier is evaluated using a one tone input signal. A center frequency 3.55 $\mathrm{GHz}$ is selected and input power levels (RFpower) swept from $0 \mathrm{dBm}$ to $30 \mathrm{dBm}$ to assess the power added efficiency (PAE), gain and output power. The simulated output power and PAE with one tone signal are illustrated in Fig. 5 (a) and (b), respectively. A $59 \%$ of PAE is achieved at $1 \mathrm{~dB}$ compassion point as can be seen in Fig. 5 (b).

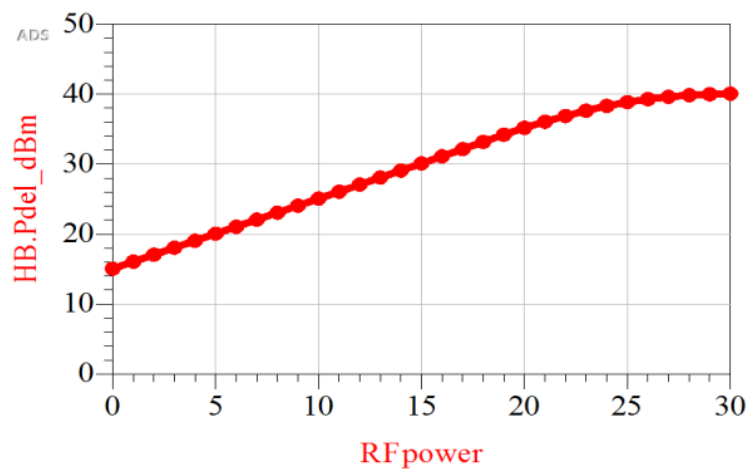

(a)

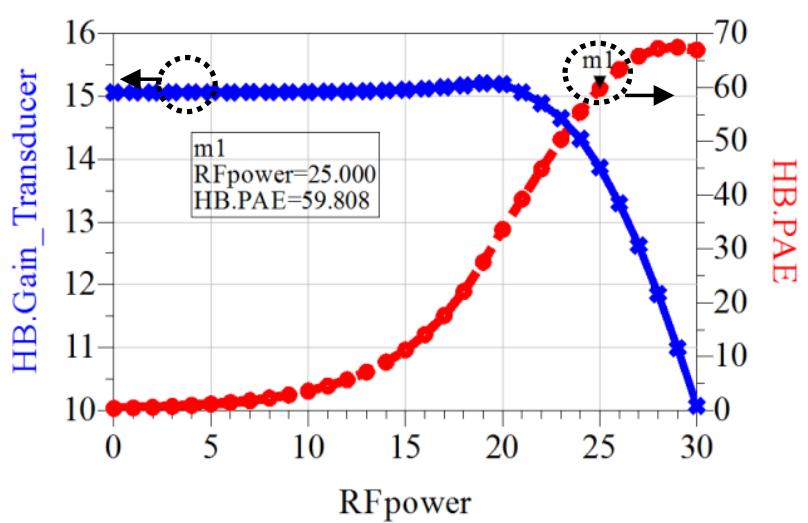

(b)

Fig. 5 One tone input signal results, (a) output power, (b) transducer gain and PAE.

Fig. 6 shows the simulated drain current and voltage waveforms at higher input power $(23 \mathrm{dBm}$ to $25 \mathrm{dBm})$. As can be observed from Fig. 6 , the waveforms of drain voltage at high input power ( $23 \mathrm{dBm}$ to $25 \mathrm{dBm}$ ) are sinusoidal, thus indicate a linear operation. Waveforms of drain current indicate class $\mathrm{AB}$ mode operation since its conduction angle is greater than $180^{\circ}$ and turned-off before completing a full cycle.

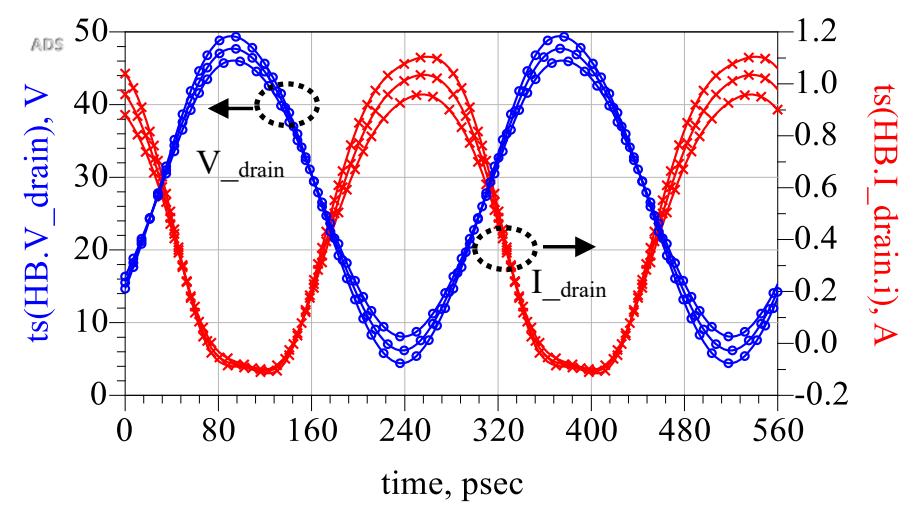

Fig.6 Drain voltage and current waveforms of the proposed power amplifier.

The non-linearity of the power amplifier creates difficulties in wireless communication systems as the RF modulated signal 
is distorted and recovering the transmitted information becomes challenging [9]. One of the most popular techniques to evaluate non-linearity behavior of power amplifier is by finding its carrier to intermodulation ratio $(\mathrm{C} / \mathrm{I})$. Defined her to be, the ratio of useful component output power to the intermodulation distortion (IMD) output power [1]. In this technique, two tone signal with more than one carrier frequency is applied at the input of the power amplifier resulting in intermodulation distortion products of side bands. Third-order intermodulation product (IM3) is the most critical source of distortion provided by two tone signals [14]. It appears at near or inside the desired signal band.

Fig. 7 shows the simulated results of upper and lower sides IM3, and IM5 of the proposed Class AB power amplifier. The input of the power amplifier is excited using two tone signals, both have the same amplitude with $5 \mathrm{MHz}$ tone spacing. The frequency is wept from $3.4 \mathrm{GHz}$ to $3.7 \mathrm{GHz}$ and input power also swept from $0 \mathrm{dBm}$ to $30 \mathrm{dBm}$. At $37 \mathrm{dBm}$ output power, the upper and lower sides of IM3 are below $-20 \mathrm{dBc}$, and IM5 is below $-40 \mathrm{dBc}$, respectively as can be observed from Fig. 7.

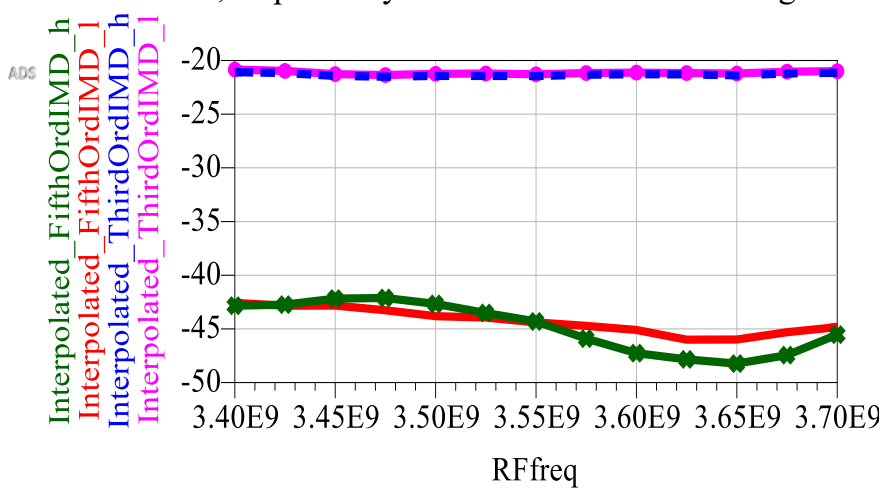

Fig. 7 Upper and lower sides third-order IMD $(\mathrm{dBc})$, and fifth-order IMD $(\mathrm{dBc})$ of the proposed amplifier at $37 \mathrm{dBm}$ output power and two tone input signal.

Fig. 8 (a) and (b) shows the output power, PAE, and transducer gain versus input power $(0 \mathrm{dBm}$ to $30 \mathrm{dBm})$ at frequency band $3.4 \mathrm{GHz}$ to $3.7 \mathrm{GHz}$ with two tone signal. At 1 $\mathrm{dB}$ compression, output power varies with frequency as can be seen in Fig. 8 (a). However, the output power is constantly greater than $36 \mathrm{dBm}$ for all frequencies within desired band at 1 $\mathrm{dB}$ compression. The PAE is greater than $47 \%$ within desired frequency band, see Fig. 8 (b).

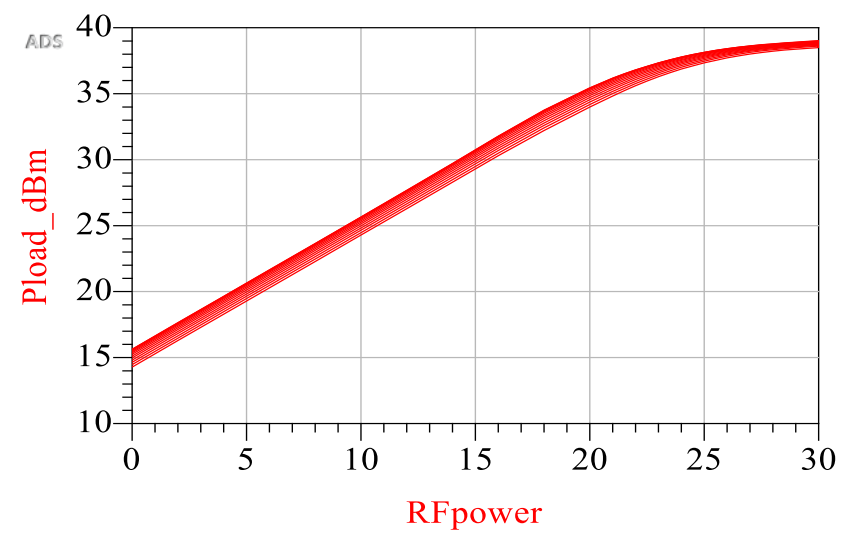

(a)

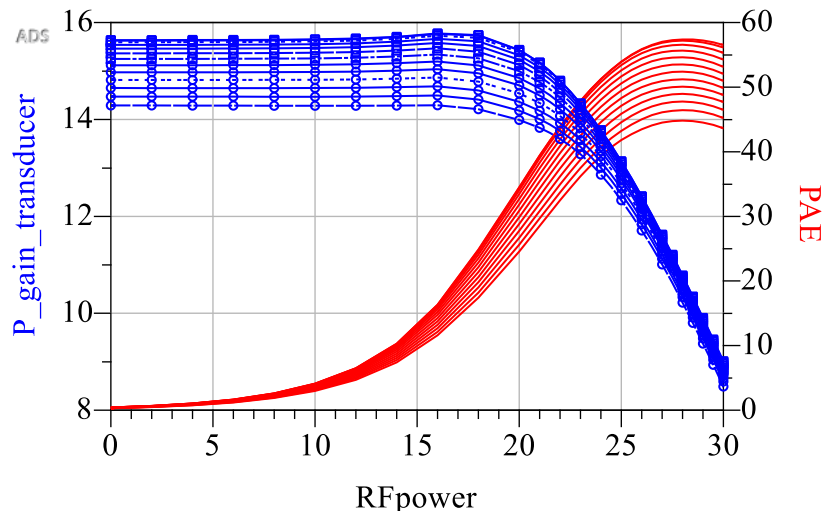

(b)

Fig. 8. Two tone input signal results, (a) output power, (b) transducer gain and PAE.

A modulated signal reverse-link CDMA with a bit rate of $1.2288 \mathrm{Mcps}$ at center frequency $3.55 \mathrm{GHz}$ is evaluated using ADS2016 software to verify the operation of the proposed design. Fig. 9 (a) and (b) illustrates the simulated results of the power amplifier with CDMA signal. The simulated result of PAE is $51.95 \%$ at output power of $37 \mathrm{dBm}$, and $22 \mathrm{dBm}$ input power. Fig. 9 (b) demonstrates the Adjacent Chanel Power Ratio (ACPR) of the power amplifier. ACPR is less than $-40 \mathrm{dBc}$ at the offsets of $2.25 \mathrm{MHz}$ for $33 \mathrm{dBm}$ (average output power) and it is below $-28.5 \mathrm{dBc}$ for the maximum output power $37 \mathrm{dBm}$ $(\sim 5 \mathrm{~W})$.
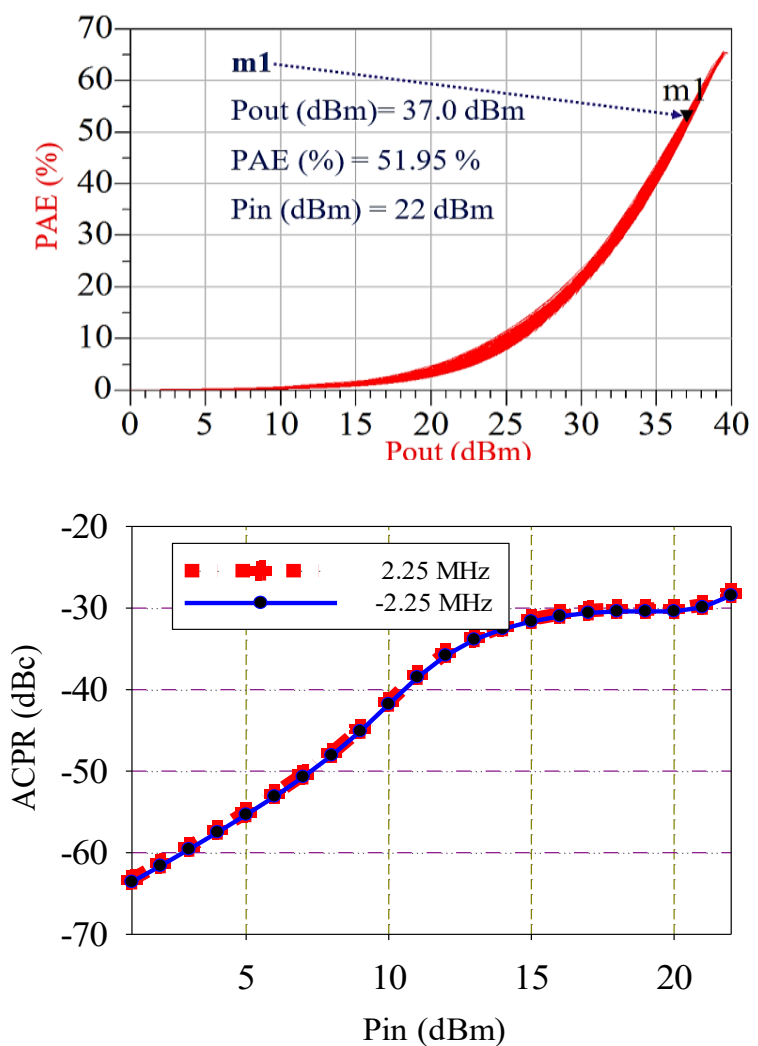

(b)

Fig.9 Simulated results of the proposed power amplifier with CDMA signal, (a) PAE, (b) ACPR. 


\section{CONCLUSION}

In this paper, a $5 \mathrm{~W}$ high efficiency Class $\mathrm{AB}$ power amplifier operates at $3.4 \mathrm{GHz}-3.7 \mathrm{GHz}$ for LTE base station applications is presented. The design procedure includes DC basing, input/output matching networks, extracting Sparameters, stability and small signal gain are discussed. One tone signal, two tone signal and CDMA signal are used to evaluate the performance of the presented power amplifier. A $51.95 \%$ of PAE, less than $-28 \mathrm{dBc}$ of ACPR, and $37 \mathrm{dBm}$ output power are achieved with CDMA signal.

\section{ACKNOWLEDGMENT}

This publication has emanated from research conducted with the financial support of Science Foundation Ireland (SFI) and is co-funded under the European Regional Development Fund under Grant Number 13/RC/2077.

\section{REFERENCES}

[1] S. C. Cripps, RF Power Amplifiers for Wireless Communications 2nd ed., Boston: Artech House, 2006.

[2] M. Rumney, LTE and the evolution to $4 G$ Wireless: Design and measurement challenges, John Wiley \& Sons, 2012.

[3] K. Niotaki, A. Georgiadis, J. Vardakas and A. Collado, "5 Watt GaN Hemt Power Amplifier for LTE," Radio Engineering, vol. 23, no. 1, pp. 338-344, 2014.
[4] I. Mustazar, and A. Piacibello. "A 5W class-AB power amplifier based on a GaN HEMT for LTE communication band." 16th Mediterranean Microwave Symposium (MMS), IEEE, 2016.

[5] Grebennikov, Andrei. $R F$ and microwave power amplifier design. NewYork: McGraw-Hill, 2005.

[6] Yeom, Kyung-Whan. Microwave Circuit Design: A Practical Approach Using ADS. Prentice Hall Press, 2015.

[7] P. Colantonio, F. Giannini and E. Limiti, High Efficiency $R F$ and Microwave Solid State Power Amplifier, Chichester, U.K.: J. Wiley, 2009

[8] Walker, John LB, ed. Handbook of RF and microwave power amplifiers. Cambridge university press, 2011.

[9] I. J. Bahl, Fundamentals of RF and Microwave Transistor Amplifiers, Hoboken, N.J.: Wiley, 2009.

[10] Vassilakis, B., and A. Cova. "Comparative analysis of $\mathrm{GaAs} / \mathrm{LDMOS} / \mathrm{GaN}$ high power transistors in a digital predistortion amplifier system." Asia-Pacific Micro. Conf. (APMC).. Vol. 2, 2005.

[11] Mishra, Umesh K., et al. "GaN-based RF power devices and amplifiers." Proceedings of the IEEE 96.2, 287-305, 2008.

[12] Kikkawa, Toshihide, et al. "High performance and high reliability AlGaN/GaN HEMTs." physica status solidi (a), 206.6, 1135-1144, 2009.

[13] N. Khalid, T. Abbas and M. Bin Ihsan, "Power amplifier design using GaN HEMT in class-AB mode for LTE communication band," Inter. Wirel. Communi. and Mobi. Comput.Conf. (IWCMC), Dubrovnik, 2015, pp. $685-689$.

[14] N. B. Carvalho and J. C. Pedro, "Two-tone IMD asymmetry in microwave power amplifier," Microwave Symposium Digest. 2000 IEEE MTT-S International, vol. 1, pp. 445 - 448, 2000. 